\title{
Impact of seasonal variation in meteorological conditions on dry eye severity
}

This article was published in the following Dove Press journal:

Clinical Ophthalmology

\author{
Harrison Dermer' \\ Anat Galor ${ }^{2,3}$ \\ Abigail S Hackam ${ }^{3}$ \\ Mehdi Mirsaeidi ${ }^{2-4}$ \\ Naresh Kumar ${ }^{5}$ \\ 'Miller School of Medicine, University \\ of Miami, Miami, FL, USA; ${ }^{2}$ Eye Care \\ (Ophthalmology), Miami Veterans \\ Affairs (VA) Medical Center, Miami, \\ FL, USA; ${ }^{3}$ Ophthalmology Department, \\ Bascom Palmer Eye Institute, Miami, \\ FL, USA; ${ }^{4}$ Divison of Pulmonary, \\ Critical Care, Sleep and Allergy, \\ Department of Medicine, University \\ of Miami, Miami, FL, USA; ${ }^{5}$ Public \\ Health Sciences, Environmental \\ Health Division, University of Miami, \\ Miami, FL, USA
}

Purpose: To compare dry eye (DE) diagnosis patterns by season in Miami vis-a-vis the US and examine differences in DE symptoms and signs by season in Miami.

Patients and methods: US veteran affairs (VA) patient visits with ICD-9 codes for DE (375.15) and routine medical examination (V70.0) from 2010 to 2013 were retrospectively analyzed to evaluate the seasonal pattern of DE diagnosis. A total of 365 patients with normal ocular anatomy were prospectively recruited from the Miami VA eye clinic from 2014 to 2016 for the assessment of symptoms and signs.

Results: While DE visit prevalence in Miami was about 10\% lower than that of the rest of the country (22.5\% vs 33.7\%), Miami had roughly four times higher variability in DE visit prevalence throughout the year than the US. Peak values for DE symptoms in the Miami cohort aligned with peak DE prevalence seen in the retrospective sample, occurring in spring and fall. A similar, but less dramatic, pattern was noted with DE signs. The seasonal pattern in DE symptoms remained even after controlling for confounders including demographics and medication use.

Conclusion: DE symptoms, and to a lesser degree signs, varied by month, with the highest severity of symptoms occurring in spring and fall, which corresponded with peak allergy season and weather fluctuations, respectively. These findings have important implications for seasonspecific diagnosis, treatment, and management of DE.

Keywords: seasonality, DE signs and symptoms, weather, pollen, United States, epidemiology

\section{Introduction}

Dry eye (DE) is a highly prevalent disease, with one in four patients reporting DE symptoms to their eye care provider. ${ }^{1}$ Symptoms, including blurry vision and eye pain, negatively impact the patients' quality of life and affect their ability to perform activities of daily living. ${ }^{2-4}$ Signs of DE are varied and include decreased tear production, increased tear evaporation, elevated tear osmolarity, and/or ocular surface disruption. ${ }^{4}$ This situation is further complicated by the report that symptoms and signs of DE often do not correlate. ${ }^{5}$

Many internal and external factors have been implicated in the onset and persistence of DE, including diet, hormone levels, lifestyle factors, and environmental exposures, particularly meteorological conditions. ${ }^{6}$ While most of these variables are relatively constant throughout the year, meteorological conditions vary by season. In fact, studies support a seasonal pattern in the prevalence of DE in the US $\mathrm{US}^{7,8}$ and other parts of the world. ${ }^{9}$ Specifically, a nationwide retrospective analysis of US veterans found that the diagnosis of DE had a seasonal pattern, with the maximum prevalence in winter and spring. ${ }^{7}$ Yet, we still do not fully understand the role of seasonality in specific DE symptoms and signs.
Correspondence: Naresh Kumar Environmental Health Division, University of Miami, I I20 NW 14th St, Miami,

FL 33136, USA

Tel +I 3052434854

Email nkumar@miami.edu 
There is biological plausibility that changing meteorological conditions across seasons can both directly and indirectly impact the tear film and ocular surface. For example, high temperature and low humidity increased intracellular stress in an in vitro model, ${ }^{10}$ and thus may impact corneal epithelial cells. These conditions also increase the rate of desiccating tear film evaporation and aqueous loss, ${ }^{11,33}$ ultimately negatively impacting the ocular surface. The changing meteorological conditions can indirectly modify the exposure of the eye to air pollutants and allergens. For example, heat, humidity, wind, and atmospheric pressure alter the concentration, type, and composition of air pollutants by atmospheric physical and chemical processes. ${ }^{12,13}$ High wind velocity facilitates the dispersion of outdoor particles and reduces their concentration, and high temperature and solar radiation enhance photochemical reactions, resulting in high concentration of surface ozone. Moreover, high relative precipitation and temperature facilitate the production of bioaerosols including pollens and mold spores that have been linked to ocular surface inflammation and DE. ${ }^{7,14}$

As the impact of meteorological conditions on DE has not been fully elucidated, in the present study we used seasonality as a proxy for meteorological conditions and examined its role in DE. We did so by first comparing DE prevalence in Miami versus that in the US and then focusing on sepcific DE symptoms and signs in a well-defined Miami-based population. The knowledge gained from this research can provide insight into the effect of changing meteorological conditions across seasons on DE and help to develop a better understanding of the differential role of environmental exposures across seasons in DE pathogenesis.

\section{Materials and methods}

This research relied on two different data sets: 1) national retrospective data from all US veteran affairs (VA) facilities and 2) Miami VA cohort.

\section{USVA retrospective data}

We used the national VA database to extract all visits to any VA facility within the continental US between 2010 and 2013. ICD-9 diagnosis codes were then examined, and individuals with a code for DE (375.15) were identified. This DE code encompasses various DE subtypes (evaporative, aqueous deficiency, symptoms only). As the total population at risk, ie, all veterans covered by a VA facility, was unknown, we used routine medical visit code (V70.0) to compute a standardized rate of $\mathrm{DE}$ prevalence, ie, the ratio of $\mathrm{DE}$ diagnosis to DE diagnosis plus routine medical visits (V70.0).

\section{Miami DE cohort}

South Florida residents with normal eyelid and corneal anatomy were recruited from the Miami VA Healthcare eye clinic between January 2014 and December 2016. Inclusion was limited to patients who did not plan to spend significant time away from home before or during the data collection period. Patients were excluded from participation if they had ocular or systemic conditions that could confound DE, including contact lens wear, a history of refractive surgery, use of ocular medications with the exception of artificial tears, an active external ocular process, cataract surgery in the last 6 months, or a history of glaucoma or retinal surgery. ${ }^{15}$ Furthermore, individuals with a diagnosis of HIV, sarcoidosis, Sjögren's syndrome, graft-versus-host disease, or collagen vascular disease were excluded. All patients examined in the eye clinic who met the inclusion and exclusion criteria were offered participation in the study. Interested patients were scheduled for a study visit in which written informed consent was obtained and DE parameters were measured. The study was approved by the Miami VA Institution Review Board (IRB approval \#3011.02). The study was conducted in accordance with the principles of the Declaration of Helsinki and complied with the requirements of the United States Health Insurance Portability and Accountability Act.

\section{Measures}

Questionnaires: For each individual, demographic information (age, sex, race, and ethnicity), past ocular and medical history, and medication information was collected. Patients filled standardized questionnaires regarding DE symptoms, including the dry eye questionnaire 5 (DEQ5) ${ }^{16}$ and the ocular surface disease index (OSDI) ${ }^{17}$ The Neuropathic Pain Symptom Inventory (NPSI), modified for the eye (NPSI-E), ${ }^{18}$ was used to quantify the severity of clinically relevant dimensions of neuropathic pain. To modify the NPSI so that it was relevant to neuropathic ocular pain (NOP), we replaced three of the original questions regarding the severity of allodynia or hyperalgesia with questions specific to ocular allodynia or hyperalgesia (eye pain caused or increased by [1] wind, [2] light, and [3] heat or cold), as previously described in the literature. ${ }^{19}$

Ocular surface evaluation: All patients underwent a standardized ocular surface examination by an investigator masked to the questionnaire data, which included measurement of 1) tear osmolarity (TearLab Osmolarity System, TearLab, San Diego, CA, USA) (once in each eye); 2) tear evaporation measured as tear breakup time (TBUT) 
( $5 \mu \mathrm{L}$ fluorescein instilled in the superior conjunctiva, time measured in seconds until the first black spot appeared in the tear film, 3 measurements taken with 5-second blink interval between measurements and averaged); 3) corneal epithelial cell disruption measured by corneal staining (National Eye Institute [NEI] scale, 5 areas of the cornea assessed; score 0-3 in each area, total score: 15); and 4) Schrimer score with anesthesia measured as millimeter of wetting at 5 minutes. For each individual, data from the more severely affected eye (lower value for TBUT and Schirmer, higher value for staining and osmolarity) were used in the analyses.

\section{Statistical analyses}

For the retrospective analysis, DE visit prevalence (computed as the ratio of $\mathrm{DE}$ diagnosis to routine medical examination visit plus DE diagnosis) was estimated. Descriptive statistics of DE prevalence were then computed and plotted by months. A coefficient of variance was calculated (SD/mean DE visit prevalence) to examine relative variability across months in Miami and the rest of the US.

For the prospective analysis, seasonal distribution and descriptive statistics for patient's demographics, comorbidities, medication use, and mental health were calculated and compared by ANOVA, chi-square test, or Fisher's exact tests, as appropriate. Differences in DE symptoms and signs by month and season were examined using descriptive statistics. All DE symptoms and signs were modeled using multilevel mixed-effects linear regression (STATA function xtmixed). ${ }^{20}$ Because some patients were examined twice, patient was used as a panel variable, and the error term was adjusted for patient-specific random effect. Because month number was coded as a linear distribution (coded as $1=$ January, $2=$ February, ..., 12 = December), this could not be used to represent cyclic seasonal pattern of DE prevalence; therefore, the month number was cos transformed with the maximum values corresponding to spring and fall and minimal values corresponding to summer and winter, which coincided with cyclic distribution of DE prevalence in Miami. The model also included selected demographics and comorbidities that were significantly different across seasons (Supplementry material). All analyses were conducted in R (Version 3.3) $)^{21}$ and Stata (Version 14). ${ }^{20}$

\section{Results \\ DE visit prevalence in Miami and US veteran populations}

There were 6,198 visits with a DE diagnosis in Miami compared to 993,998 visits with a DE diagnosis in the US. Similarly, there were 21,405 wellness (or routine) visits in Miami compared to 1,952,141 visits in the US. The DE visit prevalence in Miami with respect to the routine examination visit was $22.5 \%$, which was about $10 \%$ lower than that of the rest of the country $(33.7 \%)$.

\section{Monthly DE diagnosis prevalence in a Miami veteran population}

Figure 1 shows the monthly distribution of DE visit prevalence in Miami and the rest of the US. While Miami exhibited

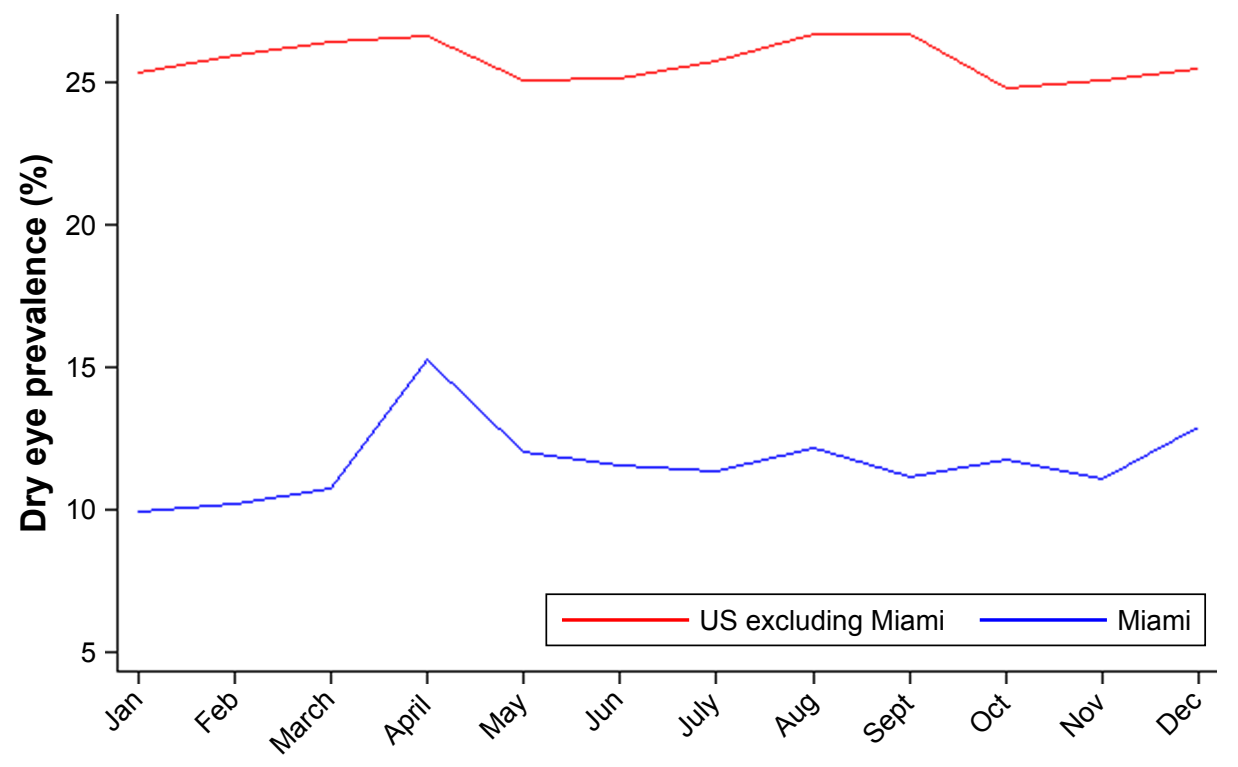

Figure I Dry eye prevalence in US and Miami by months, 2010-2013.

Abbreviation: DE, dry eye. 
a strong seasonal pattern with elevated DE visit prevalence in spring, the rest of the country exhibited less of a seasonal pattern, with less prominent bimodal peaks in spring and early fall. Table S1 lists DE visit prevalence by month for the US and Miami. April (25.9\%), May (25.2\%), and December (24.3\%) showed the highest prevalence in Miami, and April was also high for the US as a whole $(34.6 \%)$. The other monthly maxima for the US were March (34.5\%), August (34.7\%), and September (34.6\%). Prevalence peaked in the spring for both locations, and secondary peaks occurred in early fall for the US, but not until winter in Miami. The lowest prevalence occurred in February in Miami and in October in the US. These minima occurred within two months of a peak for both the US and Miami. A comparison of the coefficient of variances between the two groups highlighted that Miami had roughly four times higher monthly variability in DE visit prevalence than the US $(8.4 / 2.2=3.81)$.

\section{Miami veteran study population}

Between 2014 and 2016, 365 individuals were evaluated in the Miami VA eye clinic, of which 333 individuals were examined once and 32 individuals were examined twice (total number of visits $=397$ ). The mean age of the population was 61.8 years, 336 (92\%) were male, and 182 (50\%) selfidentified as white and $100(27.4 \%)$ as Hispanic (Table S2). For this table, demographics and comorbidity data for the 32 individuals with multiple visits were recorded only once, during their first visit. The frequency of a few variables differed by season, including race, use of anxiolytic, and antihistamine use.

\section{DE symptoms in a Miami veteran population}

Peak DE symptom severity occurred in spring and fall (Table 1; Figure 2), corresponding to the peak DE prevalence measured in the retrospective national sample. Conversely, symptom questionnaire score means were lowest in January and July. Specifically, the mean OSDI scores were highest in September. The mean OSDI scores were in the severe range $(>33)^{17}$ in every month except January and July, with the most severe scores $(>40)^{22}$ occurring in spring and fall. DEQ5 scores peaked in February, followed by April and October. These were the only months where the aggregate mean DEQ5 score was in the severe range $(>12) .{ }^{16}$ NPSI-E scores also peaked in February, with the other maximum values again occurring in spring and fall. Figure 2 visually demonstrates the bimodal distribution of DE symptoms.

\section{DE signs in a Miami veteran population}

Summary statistics for DE signs were computed by month (Table 2; Figure 2). Corneal staining demonstrated the most variation by month, followed by Schirmer score and TBUT. Staining for corneal epithelial disruption was the most

Table I DE symptom questionnaire scores by month from 2014 to 2016 , including multiple visits

\begin{tabular}{|c|c|c|c|c|c|}
\hline Month (n) & $\begin{array}{l}\text { OSDI } \\
(\text { range } 0-100) \\
\text { mean } \pm \text { SD }\end{array}$ & $\begin{array}{l}\text { DEQ5 (range 0-22) } \\
\text { mean } \pm \text { SD }\end{array}$ & $\begin{array}{l}\text { NPSI-E } \\
(\text { range 0-100) } \\
\text { mean } \pm \text { SD }\end{array}$ & $\begin{array}{l}\text { Evoked pain to } \\
\text { wind (range } 0-10) \\
\text { mean } \pm \text { SD }\end{array}$ & $\begin{array}{l}\text { Evoked pain to } \\
\text { light (range } 0-10) \\
\text { mean } \pm \text { SD }\end{array}$ \\
\hline January (38) & $27.61 \pm 20.13$ & $9.6 I \pm 5.98$ & $|4.87 \pm| 5.94$ & $1.42 \pm 2.19$ & $1.39 \pm 2.11$ \\
\hline February (37) & $40.4 I \pm 26.44$ & $|2.46 \pm 5.2|$ & $29.73 \pm 25.49$ & $3.73 \pm 3.83$ & $4.35 \pm 3.90$ \\
\hline March (37) & $36.72 \pm 29.15$ & $11.22 \pm 5.75$ & $21.22 \pm 20.90$ & $3.05 \pm 3.27$ & $3.95 \pm 4.05$ \\
\hline April (33) & $38.79 \pm 22.39$ & $12.36 \pm 3.94$ & $27.97 \pm 21.04$ & $3.21 \pm 3.35$ & $3.82 \pm 2.96$ \\
\hline May (4I) & $39.29 \pm 23.84$ & $11.83 \pm 4.61$ & $22.05 \pm 22.77$ & $3.24 \pm 3.19$ & $3.37 \pm 3.39$ \\
\hline June (3I) & $34.82 \pm 27.80$ & 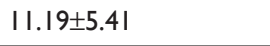 & $18.45 \pm 20.96$ & $2.61 \pm 3.47$ & $2.68 \pm 3.27$ \\
\hline July (3I) & $28.18 \pm 26.72$ & $9.94 \pm 5.40$ & $13.52 \pm 20.00$ & $2.19 \pm 3.09$ & $2.19 \pm 2.96$ \\
\hline August (33) & $34.44 \pm 22.80$ & $11.91 \pm 5.47$ & $24.45 \pm 24.65$ & $3.27 \pm 3.22$ & $3.45 \pm 3.54$ \\
\hline September (3I) & $47.62 \pm 26.69$ & $12.16 \pm 4.97$ & $28.07 \pm 25.46$ & $3.74 \pm 3.22$ & $4.06 \pm 3.33$ \\
\hline October (29) & $39.18 \pm 25.28$ & $12.17 \pm 4.12$ & $27.28 \pm 26.49$ & $3.3 \mathrm{I} \pm 3.4 \mathrm{I}$ & $3.14 \pm 3.18$ \\
\hline November (22) & $38.72 \pm 27.26$ & $11.09 \pm 5.67$ & $19.95 \pm 22.94$ & $3.27 \pm 3.48$ & $2.82 \pm 3.14$ \\
\hline December (34) & $35.88 \pm 28.26$ & $11.09 \pm 5.34$ & $21.21 \pm 21.76$ & $2.59 \pm 3.12$ & $3.29 \pm 3.22$ \\
\hline $\begin{array}{l}\text { Average of all } \\
12 \text { months }(n=397)\end{array}$ & $36.67 \pm 25.74$ & II. $.42 \pm 5.20$ & $22.39 \pm 22.69$ & $2.95 \pm 3.26$ & $3.22 \pm 3.36$ \\
\hline $\mathrm{CV}^{\mathrm{a}}(\%)$ & $70.20 \%$ & $45.53 \%$ & $101.31 \%$ & $110.50 \%$ & $104.19 \%$ \\
\hline
\end{tabular}

Notes: ${ }^{a} \mathrm{CV}=$ coefficient of variance $=$ (average of the SDs of the 12 months/average of the mean of the 12 months) $* 100$. Bold, three highest values; Red, maximum value.

Abbreviations: DEQ5, Dry Eye Questionnaire 5; NPSI-E, Neuropathic Pain Symptom Inventory-modified for the eye; OSDI, Ocular Surface Disease Index. 

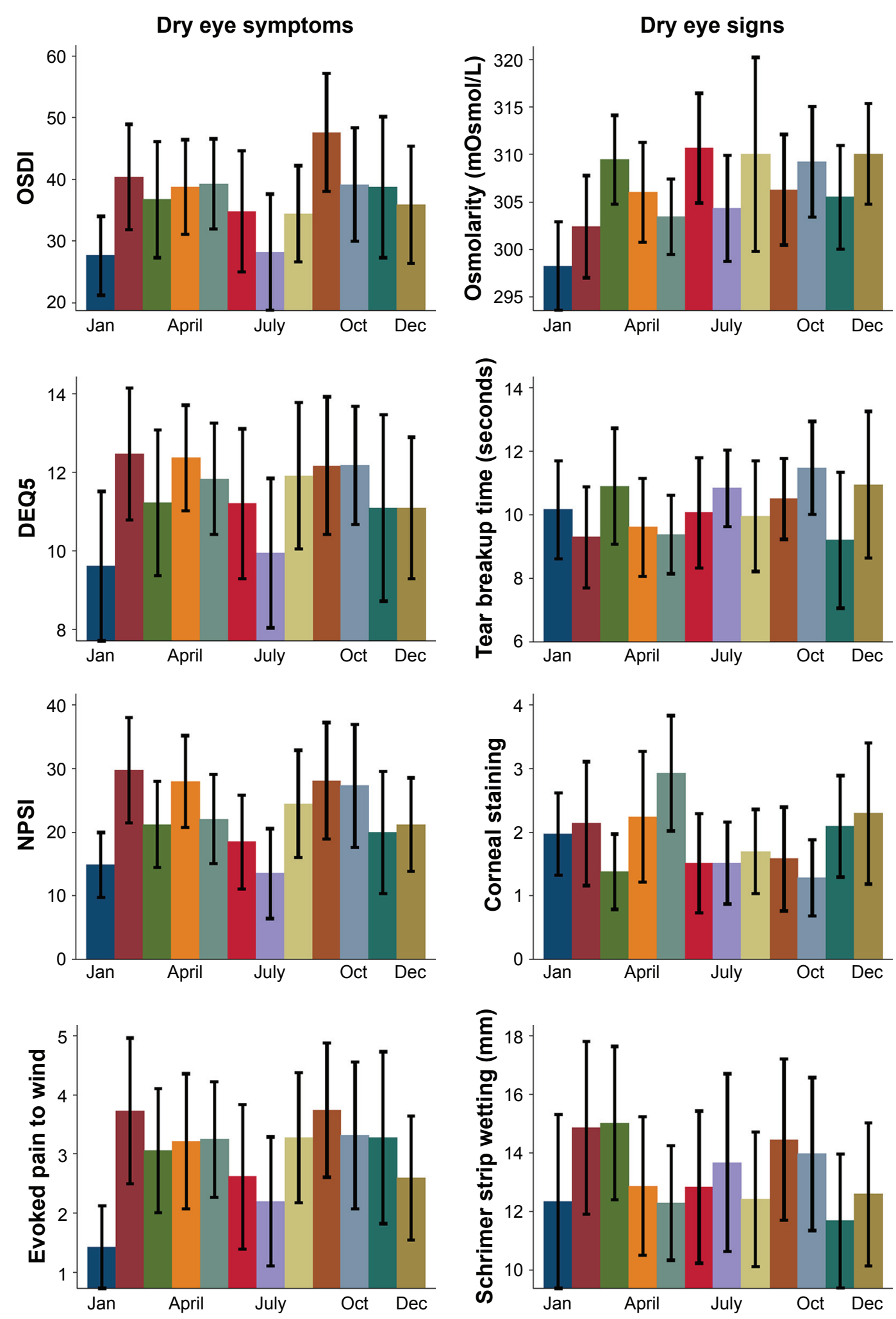

Figure 2 Monthly distribution of the selected DE symptoms and signs among Miami veterans, 20I4-20I6.

Abbreviations: DE, dry eye; DEQ5, Dry Eye Questionnaire 5; NPSI, Neuropathic Pain Symptom Inventory; OSDI, Ocular Surface Disease Index.

pronounced in spring, with peak values occurring in May. Interestingly, Schirmer scores were highest in March, corresponding with the time period of more severe symptoms. However, for Schirmer scores and TBUT, all mean levels were near or above the normal range $(>10 \mathrm{~mm}$ wetting after 5 minutes and $>10$ seconds, respectively). By comparing coefficients of variances, we noted that DE symptoms exhibited stronger monthly variability than DE signs. 
Table 2 DE tear film parameters by month from 2014 to 2016 , including multiple visits

\begin{tabular}{|l|l|l|l|l|}
\hline Month & $\begin{array}{l}\text { Osmolarity }(\mathbf{m O s m} / \mathbf{L}) \\
\text { mean } \pm \text { SD }\end{array}$ & $\begin{array}{l}\text { TBUT (seconds) } \\
\text { mean } \pm \text { SD }\end{array}$ & $\begin{array}{l}\text { Corneal staining } \\
\text { mean } \pm \text { SD }\end{array}$ & $\begin{array}{l}\text { Schirmer (mm wetting) } \\
\text { mean } \pm \text { SD }\end{array}$ \\
\hline January & $298.26 \pm 14.06$ & $10.17 \pm 4.85$ & $1.97 \pm 2.02$ & $12.35 \pm 9.17$ \\
\hline February & $302.39 \pm 16.44$ & $9.30 \pm 4.93$ & $2.14 \pm 3.01$ & $14.86 \pm 9.12$ \\
\hline March & $309.44 \pm 13.44$ & $10.91 \pm 5.66$ & $1.38 \pm 1.83$ & $15.03 \pm 8.09$ \\
\hline April & $306.03 \pm 15.41$ & $9.61 \pm 4.51$ & $\mathbf{2 . 2 4} \pm 2.99$ & $12.87 \pm 6.71$ \\
\hline May & $303.44 \pm 12.93$ & $9.38 \pm 3.97$ & $2.93 \pm 2.91$ & $12.30 \pm 6.27$ \\
\hline June & $310.68 \pm 16.36$ & $10.07 \pm 4.85$ & $1.52 \pm 2.20$ & $12.84 \pm 7.35$ \\
\hline July & $304.33 \pm 15.55$ & $10.84 \pm 3.42$ & $1.52 \pm 1.82$ & $13.68 \pm 8.58$ \\
\hline August & $310.00 \pm 24.94$ & $9.96 \pm 5.02$ & $1.70 \pm 1.93$ & $12.42 \pm 6.73$ \\
\hline September & $306.30 \pm 16.21$ & $10.51 \pm 3.61$ & $1.58 \pm 2.31$ & $14.45 \pm 7.81$ \\
\hline October & $309.21 \pm 15.95$ & $11.49 \pm 3.94$ & $1.29 \pm 1.61$ & $13.97 \pm 7.16$ \\
\hline November & $305.50 \pm 13.00$ & $9.21 \pm 5.12$ & $2.09 \pm 1.90$ & $11.68 \pm 5.43$ \\
\hline December & $310.06 \pm 15.73$ & $10.96 \pm 6.84$ & $\mathbf{2 . 2 9} \pm 3.28$ & $12.59 \pm 7.25$ \\
\hline Average of all I2 months & $306.06 \pm 16.04$ & $10.19 \pm 4.81$ & $1.91 \pm 2.43$ & $13.29 \pm 7.59$ \\
\hline CVa $(\%)$ & $5.24 \%$ & $47.19 \%$ & $127.17 \%$ & $57.13 \%$ \\
\hline
\end{tabular}

Notes: ${ }^{\mathrm{C} V}=$ coefficient of variance $=$ (average of the SDs of the 12 months/average of the mean of the 12 months) * 100 . Bold, three highest values; Red, maximum value.

Abbreviations: DE, dry eye; TBUT, tear breakup time.

\section{Monthly variation in DE symptoms and signs when adjusting for potential confounders}

Regression analyses further substantiates these findings. When adjusting for demographics and co-morbidities that varied by season (Table S2), DE symptoms, but not signs, varied significantly by month (Table 3 ). This result was of marginal significance for OSDI, DEQ5, and NPSI-E $(P<0.1)$ and significant for evoked pain to wind $(P<0.05)$. For example, OSDI scores were 3.25 points higher in spring and fall (compared to those in winter and summer, respectively). Similarly, the intensity of evoked pain to wind was 0.49 higher in spring and fall (compared to those in winter and summer, respectively). The result of our multivariable analysis is also consistent with previously noted relationships in DE. For example, older age was associated with more abnormal DE signs (staining, production, evaporation) and the use of antidepressants and anxiolytics was associated with higher DE symptoms.

\section{Discussion}

This research shows bimodal peaks for both DE diagnosis and DE symptoms in Miami and a weaker bimodal peak for a DE diagnosis in the US. The spring peak in Miami was stronger and lasted for a longer duration than that in the US. DE signs, on the other hand, when adjusted for comorbidities, did not exhibit a strong seasonal pattern.
The main findings of this research are consistent with the results of previous epidemiological studies ${ }^{7-9}$ and provide unique insights into varying DE symptoms and signs across seasons. Analysis of Google queries across multiple continents found that searches for "dry eye" were significantly more common during summer, while searches for "itchy eyes" and "conjunctivitis" also varied by season. ${ }^{23}$ Tear film composition has also been reported to change with season by increased expression of hexanoyl-lysine, a biomarker of lipid peroxidation that indicates ocular surface oxidative damage, in springtime. ${ }^{24}$

The noted bimodal distribution of DE found in our study and other studies may be explained by both direct and indirect contributions of changing weather across seasons. Seasonal variations in ambient temperature, humidity, pressure, and air current may directly aggravate $\mathrm{DE}$ by impeding lacrimal and meibomian gland function. For example, increased wind velocity directly enhances aqueous evaporation and eye irritation, ${ }^{11}$ while rising temperature has been shown to alter tear film stability by influencing lipid secretion and lipid layer functionality. ${ }^{25}$ The change in temperature between seasons probably has more influence on DE than the absolute temperature during the season. This notion is supported by the observation that the greatest decrease in DE intensity occurred in winter and summer when the weather change from the previous season was less abrupt, allowing more time for the lacrimal functional unit to acclimate. 


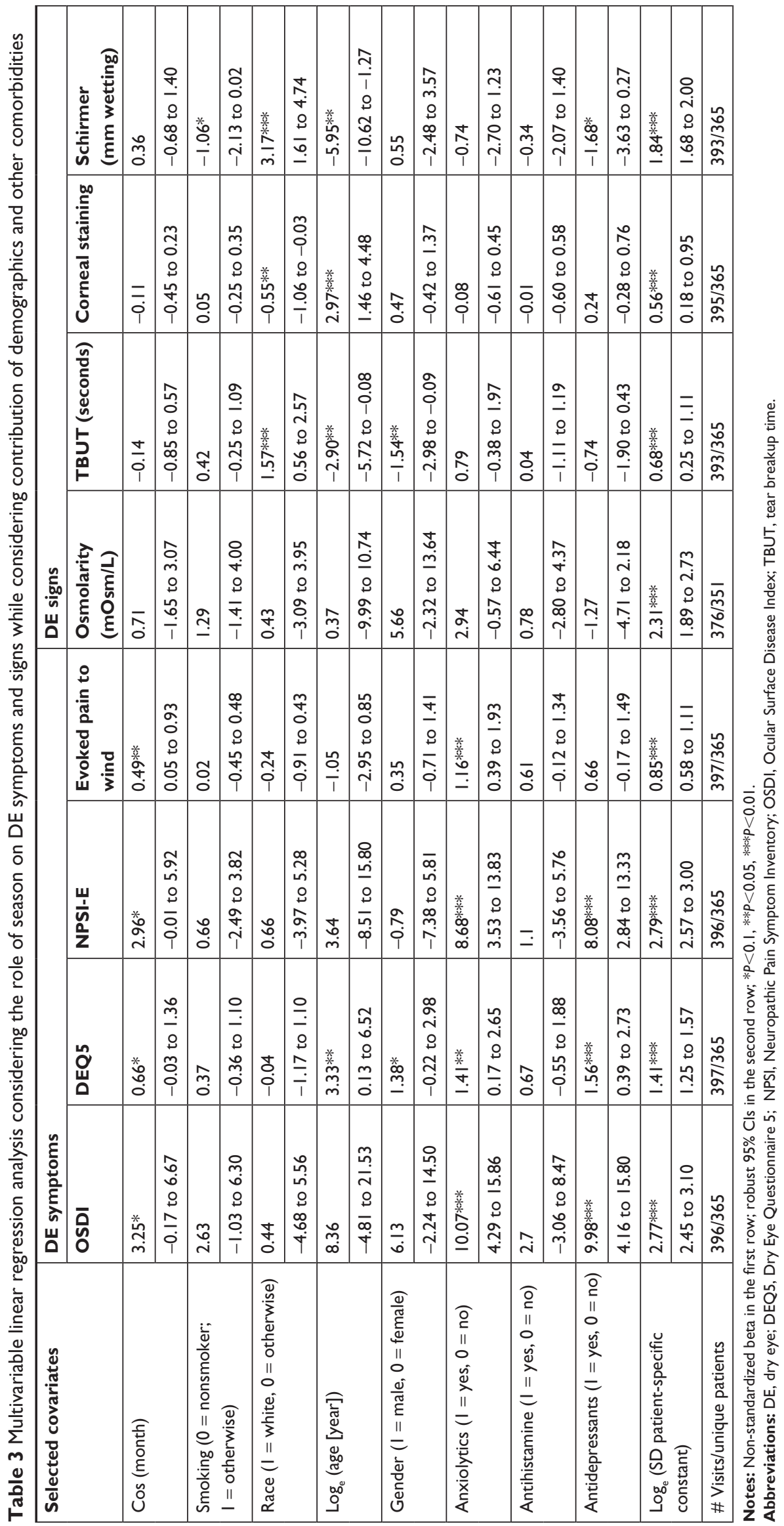


Weather conditions during springtime indirectly facilitate the production of bioaerosols such as pollen. ${ }^{7}$ Furthermore, wind speeds peak in spring, ${ }^{26}$ which facilitates dispersion of pollen. Individuals with seasonal allergic conjunctivitis have been shown to have higher DE symptoms than age- and gender-matched controls without allergies. ${ }^{27}$ Pollen can also affect the ocular surface as was shown with decreased conjunctival cell viability on exposure to pollen extract. ${ }^{28}$ Pollutants can also impact the tear film, and their concentrations can also vary by season. ${ }^{29,30}$ For example, ozone concentrations typically peak in summer and have been associated with DE symptoms in a large population-based study. ${ }^{31}$ The findings of this research must be considered in light of its limitations, which include a specific patient population, geographic location, and a cross-sectional design. The retrospective component relied on ICD diagnoses and a prevalence estimate based on a comparison to routine examination visits, whose frequency may have varied by location. Future studies are thus needed to replicate our findings in other populations and climates and to assess subclinical metrics of DE (inflammation) and specific environmental indicators (bioaerosols, air pollutants, and gases) by month and season.

\section{Conclusion}

Our findings have important implications for improving the understanding of DE pathophysiology and for developing prevention and management strategies. Identifying seasonal mechanisms allows for targeted environmental manipulations that are more cost effective and generate fewer adverse and/or side effects than current DE therapies. For example, wrap-around sunglasses may limit exposure to allergens or pollutants outdoors, particularly when needed in the spring. The use of high-quality air filters or humidifiers could improve DE manifestations when indoors, specifically during winter months. Elucidating the direct and indirect effects of seasonality on DE is especially relevant because we are likely to witness increased mean annual temperatures and weather extremes due to climate change that may intensify DE severity in patients worldwide. ${ }^{32}$

\section{Acknowledgments}

The authors note that the contents of this study do not represent the views of the Department of Veterans Affairs or the United States Government. This work in part was supported by the Department of Veterans Affairs, Veterans Health Administration, Office of Research and Development, Clinical Sciences Research EPID-006-15S (Dr Galor), R01EY026174 (Drs Kumar and Galor), NIH Center Core
Grant P30EY014801, and Research to Prevent Blindness Unrestricted Grant.

\section{Disclosure}

The authors report no conflicts of interest in this work. The authors have no financial relationships to disclose. The authors have no proprietary or commercial interest in any materials discussed in this article.

\section{References}

1. O'Brien PD, Collum LM. Dry eye: diagnosis and current treatment strategies. Curr Allergy Asthma Rep. 2004;4(4):314-319.

2. Friedman NJ. Impact of dry eye disease and treatment on quality of life. Curr Opin Ophthalmol. 2010;21(4):310-316.

3. Pouyeh B, Viteri E, Feuer W, et al. Impact of ocular surface symptoms on quality of life in a United States veterans affairs population. Am J Ophthalmol. 2012;153(6):1061-1066.e3.

4. Craig JP, Nichols KK, Akpek EK, et al. TFOS DEWS II Definition and Classification Report. Ocul Surf. 2017;15(3):276-283.

5. Galor A, Felix ER, Feuer W, et al. Dry eye symptoms align more closely to non-ocular conditions than to tear film parameters. Br J Ophthalmol. 2015;99(8):1126-1129.

6. Stapleton F, Alves M, Bunya VY, et al. TFOS DEWS II Epidemiology Report. Ocul Surf. 2017;15(3):334-365.

7. Kumar N, Feuer W, Lanza NL, Galor A. Seasonal Variation in Dry Eye. Ophthalmology. 2015;122(8):1727-1729.

8. Moss SE, Klein R, Klein BE. Prevalence of and risk factors for dry eye syndrome. Arch Ophthalmol. 2000;118(9):1264-1268.

9. van Setten G, Labetoulle M, Baudouin C, Rolando M. Evidence of seasonality and effects of psychrometry in dry eye disease. Acta Ophthalmol. 2016;94(5):499-506.

10. Meloni M, De Servi B, Marasco D, Del Prete S. Molecular mechanism of ocular surface damage: application to an in vitro dry eye model on human corneal epithelium. Mol Vis. 2011;17:113-126.

11. Abusharha AA, Pearce EI. The effect of low humidity on the human tear film. Cornea. 2013;32(4):429-434.

12. Vanos JK, Cakmak S, Bristow C, et al. Synoptic weather typing applied to air pollution mortality among the elderly in 10 Canadian cities. Environ Res. 2013;126:66-75.

13. Kumar N. A comparison of indoor and outdoor air quality and meteorological conditions in Iowa City, IA. Build Environ; 2015.

14. Ayaki M, Kawashima M, Uchino M, Tsubota R, Negishi K. Possible association between subtypes of dry eye disease and seasonal variation. Clin Ophthalmol. 2017;11:1769-1775.

15. Gomes JAP, Azar DT, Baudouin C, et al. TFOS DEWS II iatrogenic report. Ocul Surf. 2017;15(3):511-538.

16. Chalmers RL, Begley CG, Caffery B. Validation of the 5-Item Dry Eye Questionnaire (DEQ-5): Discrimination across self-assessed severity and aqueous tear deficient dry eye diagnoses. Cont Lens Anterior Eye. 2010;33(2):55-60.

17. Schiffman RM, Christianson MD, Jacobsen G, Hirsch JD, Reis BL. Reliability and validity of the Ocular Surface Disease Index. Arch Ophthalmol. 2000;118(5):615-621.

18. Kalangara JP, Galor A, Levitt RC, et al. Characteristics of Ocular Pain Complaints in Patients With Idiopathic Dry Eye Symptoms. Eye Contact Lens. 2017;43(3):192-198.

19. Galor A, Moein HR, Lee C, et al. Neuropathic pain and dry eye. Ocul Surf. 2018;16(1):31-44.

20. STATA/MP - Data Analysis and Statistical Software [computer program]. TX: College Station: Stata Corp LP; 2015.

21. R Development Core Team. R. A language and environment for statistical computing; 2012. Available from: http://www.R-project.org. Accessed November 9, 2018. 
22. Miller KL, Walt JG, Mink DR, et al. Minimal clinically important difference for the ocular surface disease index. Arch Ophthalmol. 2010; 128(1):94-101.

23. Leffler CT, Davenport B, Chan D. Frequency and seasonal variation of ophthalmology-related internet searches. Can J Ophthalmol. 2010; 45(3):274-279.

24. Haworth KM, Chandler HL. Oxidative Stress Measures of Lipid and DNA Damage in Human Tears. Invest Ophthalmol Vis Sci. 2017; 58(6):BIO151-BIO157.

25. Leiske D, Leiske C, Leiske D, et al. Temperature-induced transitions in the structure and interfacial rheology of human meibum. Biophys $J$. 2012;102(2):369-376.

26. Average Wind Speed - Florida. Florida Climate Center, Office of the State Climatologist. Available from: https://climatecenter.fsu.edu/ products-services/data/other-normals/average-wind-speed. Accessed November 28, 2017.

27. Chen L, Pi L, Fang J, Chen X, Ke N, Liu Q. High incidence of dry eye in young children with allergic conjunctivitis in Southwest China. Acta Ophthalmol. 2016;94(8):e727-e730.
28. Rabensteiner DF, Spreitzhofer E, Trummer G, et al. Pollen enzymes degrade human tear fluid and conjunctival cells: an approach to understanding seasonal non-allergic conjunctivitis. Dev Ophthalmol. 2010;45: 83-92.

29. Novaes P, Saldiva PH, Matsuda M, et al. The effects of chronic exposure to traffic derived air pollution on the ocular surface. Environ Res. 2010;110(4):372-374.

30. Wang F, Guo Z, Lin T, Rose NL. Seasonal variation of carbonaceous pollutants in PM2.5 at an urban 'supersite' in Shanghai, China. Chemosphere. 2016;146:238-244.

31. Hwang SH, Choi YH, Paik HJ, Wee WR, Kim MK, Kim DH. Potential Importance of Ozone in the Association Between Outdoor Air Pollution and Dry Eye Disease in South Korea. JAMA Ophthalmol. 2016:503.

32. Watts N, Adger WN, Agnolucci P, et al. Health and climate change: policy responses to protect public health. Lancet. 2015;386(10006): 1861-1914.

33. Abusharha AA, Pearce EI, Fagehi R. Effect of ambient temperature on the human tear film. Eye Contact Lens. 2016;42(5):308-312. 


\section{Supplementary materials}

Table SI Monthly DE visit prevalence (\%) in the US and Miami, 20I0-20I3

\begin{tabular}{|l|l|l|}
\hline Month & US & Miami \\
\hline January & $33.6 \%$ & $20.9 \%$ \\
\hline February & $34.2 \%$ & $19.5 \%$ \\
\hline March & $34.5 \%$ & $20.2 \%$ \\
\hline April & $34.6 \%$ & $25.9 \%$ \\
\hline May & $33.0 \%$ & $25.2 \%$ \\
\hline June & $32.9 \%$ & $22.5 \%$ \\
\hline July & $33.5 \%$ & $22.8 \%$ \\
\hline August & $34.7 \%$ & $22.2 \%$ \\
\hline September & $34.6 \%$ & $22.6 \%$ \\
\hline October & $32.7 \%$ & $22.3 \%$ \\
\hline November & $33.0 \%$ & $21.8 \%$ \\
\hline December & $33.5 \%$ & $24.3 \%$ \\
\hline Average of all I2 months & $33.2 \%$ & $22.5 \%$ \\
\hline Maximum-minimum value ${ }^{\mathrm{a}}$ & 2.0 & 6.4 \\
\hline Coefficient of variance & $\mathrm{b}$ & $8.4 \%$ \\
\hline
\end{tabular}

Notes: ${ }^{\mathrm{D}}$ Difference between highest and lowest frequency for DE visit prevalence. ${ }^{\mathrm{b}}$ Coefficient of variance $=\mathrm{SD} / \mathrm{mean} * 100$. Values for the months with the highest $\mathrm{DE}$ visit prevalence are shown in red.

Abbreviation: DE, dry eye. 
Table S2 Descriptive statistics of Miami VA Cohort recruited from 2014 to 2016 by season

\begin{tabular}{|c|c|c|c|c|c|}
\hline & $\begin{array}{l}\text { Winter } \\
N=100\end{array}$ & $\begin{array}{l}\text { Spring } \\
\mathrm{N}=99\end{array}$ & $\begin{array}{l}\text { Summer } \\
N=89\end{array}$ & $\begin{array}{l}\text { Fall } \\
N=77\end{array}$ & $\begin{array}{l}\text { Total } \\
N=365\end{array}$ \\
\hline Age, mean (SD; n) & $61.8 \pm 11.6$ & $62.3 \pm 10.2$ & $62.0 \pm 10.4$ & $60.7 \pm 9.1$ & $61.8 \pm 10.4$ \\
\hline \multicolumn{6}{|l|}{ Demographics, \% (n) } \\
\hline White** & $48(48.0)$ & $5 I(5 I .5)$ & $54(60.7)$ & $29(37.7)$ & $182(49.9)$ \\
\hline Black** & $48(48.0)$ & $48(48.5)$ & $35(39.3)$ & $48(62.3)$ & $179(49.0)$ \\
\hline Gender, male & $92(92)$ & $94(94.9)$ & $78(87.6)$ & $72(93.5)$ & $336(92.1)$ \\
\hline Ethnicity, Hispanic & $25(25.0)$ & $29(29.3)$ & $26(29.2)$ & $20(26)$ & $100(27.4)$ \\
\hline \multicolumn{6}{|l|}{ Smoking status, \% (n) } \\
\hline No & $15.0(15)$ & $18(18.2)$ & $20.2(18)$ & $9.1(9)$ & $15.9(58)$ \\
\hline Past & $42.0(42)$ & $52.5(52)$ & $35.6(32)$ & $53.3(4 I)$ & $45.7(167)$ \\
\hline Current & $43.0(43)$ & $29.3(29)$ & $43.8(39)$ & $37.7(29)$ & $28.4(140)$ \\
\hline \multicolumn{6}{|l|}{ Comorbidities, \% (n) } \\
\hline Hypertension & $72.0(72)$ & $74.7(74)$ & $67.4(60)$ & $70.1(54)$ & $71.2(260)$ \\
\hline Hypercholesterolemia & $60.0(60)$ & $61.6(61)$ & $57.3(5 \mathrm{I})$ & $63.6(49)$ & $60.5(221)$ \\
\hline Diabetes & $32.0(32)$ & $28.3(28)$ & $25.8(23)$ & $33.8(26)$ & $29.9(109)$ \\
\hline Osteoarthritis* & $44.0(44)$ & $49.5(49)$ & $41.6(37)$ & $62.3(48)$ & $48.8(178)$ \\
\hline Sleep apnea & $22.0(22)$ & $23.2(23)$ & $20.2(18)$ & $19.5(15)$ & $21.4(78)$ \\
\hline Benign prostatic hypertrophy* & $10.0(10)$ & $3.0(3)$ & $2.2(2)$ & $2.6(2)$ & $4.7(17)$ \\
\hline \multicolumn{6}{|l|}{ Medication use, \% (n) } \\
\hline Analgesics & $60.0(60)$ & $50.5(50)$ & $59.1(52)$ & $64.9(50)$ & $58.2(2 \mid 2)$ \\
\hline Antidepressants* & $38.0(38)$ & $48.5(48)$ & $42.7(38)$ & $58.4(45)$ & $46.3(169)$ \\
\hline Anxiolytics** & $37.0(37)$ & $47.5(47)$ & $37.1(33)$ & $63.6(49)$ & $45.5(166)$ \\
\hline Antihistamine ${ }^{* *}$ & $30.0(30)$ & II.I (II) & $23.6(21)$ & $19.5(15)$ & $21.1(77)$ \\
\hline Gabapentin/pregabalin* & $3.0(3)$ & $2.0(2)$ & $0.0(0)$ & $3.9(3)$ & $2.2(8)$ \\
\hline \multicolumn{6}{|l|}{ Mental health, \% (n) } \\
\hline Post-traumatic stress disorder & $21.0(21)$ & $23.2(23)$ & $13.5(12)$ & $16.9(13)$ & $18.9(69)$ \\
\hline Depression* & $51.0(5 \mathrm{I})$ & $61.6(61)$ & $56.2(50)$ & $72.4(55)$ & $59.6(217)$ \\
\hline
\end{tabular}

Notes: $* P \leq 0.1 ; * * P \leq 0.05$. Differences in mean age by season examined by ANOVA. Differences in frequencies of all other variables examined by the chi-square test or Fisher's exact test, as appropriate.

Clinical Ophthalmology

\section{Publish your work in this journal}

Clinical Ophthalmology is an international, peer-reviewed journal covering all subspecialties within ophthalmology. Key topics include: Optometry; Visual science; Pharmacology and drug therapy in eye diseases; Basic Sciences; Primary and Secondary eye care; Patient Safety and Quality of Care Improvements. This journal is indexed on

Submit your manuscript here: http://www.dovepress.com/clinical-ophthalmology-journal

\section{Dovepress}

PubMed Central and CAS, and is the official journal of The Society of Clinical Ophthalmology (SCO). The manuscript management system is completely online and includes a very quick and fair peer-review system, which is all easy to use. Visit http://www.dovepress.com/ testimonials.php to read real quotes from published authors. 